\title{
Short communication: Effects of frequency of feed delivery and bunk space on the feeding behavior of limit-fed dairy heifers
}

\author{
A. M. Greter, ${ }^{*}$ R. S. Westerveld, ${ }^{*}$ T. F. Duffield,† B. W. McBride, $\ddagger$ T. M. Widowski, $\ddagger$ and T. J. DeVries ${ }^{* 1}$ \\ *Department of Animal and Poultry Science, University of Guelph, Kemptville Campus, 830 Prescott Street, Kemptville, Ontario, K0G 1J0, Canada \\ †Department of Population Medicine, Ontario Veterinary College, University of Guelph, 50 Stone Road E, Guelph, Ontario, N1G 2W1, Canada \\ ‡Department of Animal and Poultry Science, University of Guelph, 50 Stone Road E, Guelph, Ontario, N1G 2W1, Canada
}

\section{ABSTRACT}

The objective of this experiment was to determine the interaction between feed bunk space and frequency of feed provision on the feeding behavior patterns and growth of growing dairy heifers fed a limited amount. Sixteen Holstein dairy heifers $(183.4 \pm 9.1 \mathrm{~d}$ of age, mean \pm standard deviation) were divided into 4 groups of 4 . The groups were exposed to each of 4 treatments, using a $4 \times 4$ Latin square design with a $2 \times 2$ factorial arrangement of treatments, over 21-d periods (14-d adaptation period, 7-d data collection periods). The treatments were arranged in 2 feed delivery frequencies (once per day at $1200 \mathrm{~h}: 1 \times / \mathrm{d}$, and twice per day at 1200 and $1400 \mathrm{~h}: 2 \times / \mathrm{d}$ ) and 2 levels of feed bunk space (adequate feed bunk space: $0.40 \mathrm{~m} /$ heifer, and reduced feed bunk space: $0.29 \mathrm{~m} /$ heifer). Pen dry matter intake (DMI) was recorded daily, average daily gain (ADG) was recorded weekly, and variability in ADG was calculated from the standard deviation of ADG. Feeding, unrewarded behavior (time at feed bunk without feed present), and competitive behavior were recorded using time-lapse video. Feeding and unrewarded behavior were measured for the last $7 \mathrm{~d}$ of each period, whereas competitive behavior was recorded on d 16, 18, and 20 of each period. Lying time was recorded for the last 7 $\mathrm{d}$ of each period. A tendency for interaction between feed bunk space and frequency of feed delivery on the feed efficiency of limit-fed dairy heifers was noted. Heifers provided restricted bunk space were reported as being less efficient when fed $2 \times / d$; however, no other interactions were found. Although DMI and variability in ADG were similar between treatments, ADG was higher $(1.0$ vs. $0.9 \mathrm{~kg} / \mathrm{d})$ when heifers were provided with $0.40 \mathrm{~m}$ of feed bunk space and tended to be higher when fed $1 \times / d$ compared with that of heifers given restricted bunk space or fed $2 \times /$ d. Heifers fed $1 \times / d$ spent more time feeding throughout the day (70.5 vs.

Received July 31, 2012.

Accepted November 20, 2012.

${ }^{1}$ Corresponding author: tdevries@uoguelph.ca
$58.9 \mathrm{~min} / \mathrm{d}$ ) than heifers fed $2 \times / \mathrm{d}$. Heifers fed at a restricted bunk space or fed $1 \times / d$ were approximately $25 \%$ more variable in feeding time than heifers fed $2 \times / d$ or with adequate bunk space. Heifers spent a similar amount of time in unrewarded visits to the feed bunk $(28.9 \mathrm{~min} / \mathrm{d})$. Although feed bunk space did not affect competition (3.6 displacements/d), heifers fed $1 \times / d$ were displaced twice as frequently than heifers fed $2 \times /$ d. Regardless of treatment, heifers spent a similar amount of time lying down and standing without eating. Overall, providing sufficient feed bunk space to allow all limit-fed heifers to feed simultaneously improves feed efficiency and ADG and reduces variability in feeding time. Additionally, although delivering feed $1 \times / d$ resulted in increased competition, it also enabled heifers to gain adequate weight and spend more time feeding each day.

Key words: dairy heifer, feeding behavior, feeding frequency, feed bunk space

\section{Short Communication}

Recent interest in limit-feeding strategies has driven an increase in research relating to heifer feeding management. Limit feeding involves providing a nutrientdense ration - composed of high levels of concentrate, high-quality forages, or a combination - to heifers in a restricted quantity. This feeding strategy has many benefits, including a decrease in fecal excretion (and subsequent nitrogen excretion), reduced feed costs, increased feed efficiency, and effective control of ADG (Hoffman et al., 2007; Lascano et al., 2009; Kitts et al., 2011).

Despite the many demonstrated benefits to limit feeding, several behavioral, health, and welfare concerns are associated with the practice. These include decreased feeding and lying time, and increased unrewarded time at the feed bunk, vocalizations, and inactive standing time (Hoffman et al., 2007; Kitts et al., 2011; A. M. Greter; O. AlZahal, Department of Animal and Poultry Science, University of Guelph, Guelph, ON, Canada; T. F. Duffield; B. W. McBride; T. M. Widowski; and T. J. 
DeVries; unpublished data). Additionally, rations high in fermentable carbohydrates, when rapidly consumed, leave replacement heifers susceptible to subclinical depressions in rumen $\mathrm{pH}$ (Quigley et al., 1992; Moody et al., 2007). Researchers have recently attempted to identify why these concerns arise and what factors may help diminish or eliminate them. When offered straw alongside a limit-fed TMR, heifers will begin consuming the straw immediately upon completion of the TMR, suggesting that they are still hungry and continue to be motivated to feed (Greter et al., 2011; Kitts et al., 2011). In a more recent study, we demonstrated that increased frequency of delivery of a limit-fed TMR did not result in a return to more natural feeding patterns, as heifers fed more frequently $(2 \times$ or $4 \times / d)$ spent less time feeding throughout the day (less than $1 \mathrm{~h}$ ) and more time standing without eating than heifers fed $1 \times / d$ (Greter et al., unpublished data). We speculated that this was due to high feeding motivation in these animals. Additionally, in that study, variability in ADG between individuals within a pen was greater when heifers were fed more frequently.

One of the essential management aspects associated with limit feeding is the amount of feeding space needed for heifers to feed simultaneously. When limit-fed heifers lack adequate space, the level of competition at the feed bunk increases, time spent feeding decreases, and variability in growth between heifers increases (Keys et al., 1978; Longenbach et al., 1999). Alternatively, providing more than adequate space ( 0.68 vs. $0.34 \mathrm{~m} /$ heifer $)$ has been shown to have no benefit on the behavior of limitfed heifers (Greter et al., 2011). Zanton and Heinrichs (2008) recently suggested that, when feed bunk space is insufficient for limit-fed heifers to feed simultaneously, producers should consider feeding $2 \times / \mathrm{d}$ at close intervals (i.e., $2 \mathrm{~h}$ apart). The untested hypothesis of these researchers was that this provides more opportunity for larger, dominant animals to feed at will after the first feed delivery and the more timid animals to feed after the second feed delivery. Unfortunately, given that limit-fed heifers consume their feed so quickly and are still motivated to feed following complete consumption of the TMR present in the bunk (Kitts et al., 2011), it could be hypothesized that the dominant heifers may return and dominate the feed bunk after the second feed delivery as well. Therefore, the objective of this experiment was to determine the interaction between feed bunk space and frequency of feed provision on the feeding behavior patterns and growth of growing dairy heifers fed a limited amount. We hypothesized that delivering a limit-fed ration twice daily $(2 \times / \mathrm{d})$ in 2 equal amounts ( $2 \mathrm{~h}$ apart) to heifers with restricted feed bunk space would result in less time feeding due to increased competition at the feed bunk compared with heifers given adequate feed bunk space and fed once per day $(1 \times / d)$.

Sixteen dairy heifers were used in this study; 8 heifers were owned by the University of Guelph, Kemptville Campus, and the remaining 8 were acquired, on loan, from a local commercial dairy operation. Upon arrival, all heifers were given a broad-spectrum antibiotic (Draxxin, tulathromycin, Pfizer Animal Health, Kirkland, Quebec, Canada) to prevent potential sickness due to transport and mixing stresses (Stanton et al., 2010) and were given a 14-d adaptation period to acclimate to groups and their environment. Heifers were $183.4 \pm 9.1 \mathrm{~d}$ of age (mean $\pm \mathrm{SD}$ ) and weighed $223.3 \pm 20.5 \mathrm{~kg}$ at the beginning of the study. Heifers weighed $312.6 \pm 29.1 \mathrm{~kg}$ at the end of the study. Heifers were housed in pens of 4 balanced for age and weight. Pens were located in a naturally ventilated barn at the University of Guelph, Kemptville Campus (Kemptville, Ontario, Canada), and were managed according to the guidelines set by the Canadian Council on Animal Care (2009). Use of heifers was approved by the University of Guelph's Animal Care Committee (AUP\#09R022), and the study was conducted between March and June 2011. Pens consisted of an indoor, sand-bedded pack area $(3.6 \mathrm{~m} \times 10.9 \mathrm{~m}$; width $\times$ depth $)$ and an outdoor concrete run $(3.6 \mathrm{~m} \times 16.4 \mathrm{~m})$. Sand bedding was cleaned out and replenished once weekly throughout the experiment. Feed bunks were located along the front of each indoor pack area and varied in length depending on treatment. Water was available ad libitum to the heifers through a water bowl in each pen and heifers were given ad libitum access to trace mineral salt blocks (Windsor TM Stock Salt, The Canadian Salt Company Limited, Pointe-Claire, Quebec, Canada).

Prior to the start of the study, all heifers had previously been fed a TMR. Upon arrival, heifers were fed a high-concentrate TMR (Table 1) that was formulated, and fed at a restricted level $(2.0 \%$ of $\mathrm{BW})$, to meet the nutrient requirements for a nonbred Holstein heifer growing at $0.9 \mathrm{~kg} / \mathrm{d}$ (NRC, 2001). Over the 14-d adaptation period, heifers were fed straw (initially offered at $8.0 \mathrm{~kg} /$ pen as-fed) alongside the TMR. This long forage was provided to stimulate rumination, chewing, and resultant buffering (Beauchemin et al., 2008) to help transition the rumen to the high-concentrate TMR. The transition was done over $8 \mathrm{~d}$; the amount of straw offered per pen was gradually reduced by $1.0 \mathrm{~kg} / \mathrm{d}$ until heifers were provided only with the high concentrate, limit-fed TMR.

Following the adaptation period, groups of heifers were exposed to each of 4 treatments, in 21-d periods, using a $4 \times 4$ Latin square design with a $2 \times 2$ factorial arrangement of treatments. The treatments included arrangement of 2 feed delivery frequencies $(1 \times / \mathrm{d}$ at 
Table 1. Chemical composition and particle size distribution (mean $\pm \mathrm{SD}$ ) of the treatment ration and the forages

\begin{tabular}{lrcc}
\hline Item & $\begin{array}{c}\text { Treatment } \\
\text { ration }^{1,2}\end{array}$ & $\begin{array}{c}\text { Corn } \\
\text { silage }\end{array}$ & $\begin{array}{c}\text { Grass/alfalfa } \\
\text { haylage }\end{array}$ \\
\hline Chemical composition & & \\
DM (\%) & & & $32.5 \pm 4.2$ \\
OM (\% of DM) & $52.0 \pm 3.7$ & $44.1 \pm 3.1$ & $87.1 \pm 0.6$ \\
CP (\% of DM) & $93.1 \pm 0.5$ & $96.7 \pm 0.2$ & $17.0 \pm 1.6$ \\
ADF (\% of DM) & $15.7 \pm 0.9$ & $8.2 \pm 0.1$ & $35.0 \pm 2.7$ \\
NDF (\% of DM) & $16.1 \pm 1.4$ & $22.9 \pm 0.7$ & $15.8 \pm 2.6$ \\
NFC (\% of DM) & $26.9 \pm 2.4$ & $37.2 \pm 1.8$ & $39.6 \pm 10.6$ \\
Particle size (\%) & $47.2 \pm 2.5$ & $49.0 \pm 1.6$ & $41.6 \pm 8.5$ \\
Long & $5.5 \pm 2.0$ & $6.3 \pm 0.8$ & $17.9 \pm 5.2$ \\
Medium & $43.0 \pm 4.5$ & $54.7 \pm 6.3$ & $0.9 \pm 0.8$ \\
Short & $45.9 \pm 3.6$ & $35.5 \pm 6.8$ & $3.6 \pm 2.0$ \\
Fine & $5.7 \pm 2.6$ & $3.6 \pm 0.9$ \\
\hline
\end{tabular}

${ }^{1}$ Ration composition (DM basis) was $20.0 \%$ corn silage, $20.0 \%$ grass/alfalfa haylage, $45.0 \%$ high-moisture corn, and $15.0 \%$ protein supplement [supplied by Dundas Feed and Seed (Winchester, ON, Canada), containing (on as-is basis) $25.6 \%$ corn gluten meal, 24.4\% Tri-Pro Gold (Tri-County Protein Corp., Winchester, ON, Canada), $24.4 \%$ soybean meal, $10.0 \%$ canola meal, $4.8 \%$ ground limestone, $4.5 \%$ trace mineral/vitamin premix, $4.4 \%$ sodium bicarbonate, $1.9 \%$ cobaltized-iodized salt].

${ }^{2}$ Chemical composition of high-moisture corn (DM basis) was $9.3 \pm 0.0 \% \mathrm{CP}, 4.0 \pm 0.2 \% \mathrm{ADF}$, and $12.0 \pm$ $0.5 \% \mathrm{NDF}$.

${ }^{3}$ Values were obtained from chemical analysis of TMR samples. NFC $=100-(\% \mathrm{CP}+\% \mathrm{NDF}+\%$ fat $+\%$ ash).

${ }^{4}$ Particle size determined by Penn State Particle Separator, which has a 19-mm screen (long), 8-mm screen (medium), 1.18-mm screen (short), and a pan (fine).

$1200 \mathrm{~h}$, and $2 \times / \mathrm{d}$ at 1200 and $1400 \mathrm{~h}$ ) and 2 levels of feed bunk space (adequate feed bunk space: $0.40 \mathrm{~m} /$ heifer, and reduced feed bunk space: $0.29 \mathrm{~m} /$ heifer), resulting in 4 treatments. Each 21-d treatment period consisted of a 14-d adaptation period (to allow heifers to acclimate to the treatment), followed by a 7 -d data collection period. The feed bunk was a fence-line feed bunk with a post-and-rail access. Once daily, dietary components were mixed in a TMR mixer wagon (Jaylor 4425, Jaylor Fabricating, Orton, Ontario, Canada), and the appropriate amount of TMR was manually weighed out for each pen. Daily feed amounts for heifers fed twice per day were divided into 2 equal amounts with the second half of feed kept in an air-conditioned room $\left(12^{\circ} \mathrm{C}\right)$ in the barn until the second delivery. The total amount of feed offered to each pen was adjusted weekly, according to average pen BW.

Group intakes were recorded daily throughout the study by weighing the amount of feed offered and amount of feed refused (if any). These data were used to calculate daily DMI $(\mathrm{kg} / \mathrm{d})$ for each pen. Heifers were weighed and measured on the same 2 consecutive days each week at $0700 \mathrm{~h}$, and the weekly weights were averaged for each heifer and used to calculate ADG.

Feeding and competitive behavior were monitored continuously, using time-lapse video, for the last $7 \mathrm{~d}$ of each treatment period. Heifers were recorded using 1 video camera (Panasonic WV-BP330, Osaka, Japan) per pen, a time-lapse video cassette recorder (Panasonic AG-6740), and a video multiplexer (Panasonic
WJ-FS 616). Video cameras were mounted $3.2 \mathrm{~m}$ above each of the 4 feed bunks. Red lights $(100 \mathrm{~W})$, mounted adjacent to the cameras, were used to facilitate recording at night. Digital photographs were taken showing a dorsal view of the back of each animal and these photos were used during video analysis to identify individuals within each pen. The amount of time spent feeding during the 7-d recording period was scored for individual heifers using instantaneous scan sampling every 1 min. For each scan, feeding was defined when a heifer had her head completely past the feed rail and over the feed. Total time spent feeding was then calculated for each heifer for each day of the 7-d recording period. To identify changes in diurnal feeding patterns between treatments, these scans were used to calculate the percentage of heifers feeding at the feed bunk over a 24-h period. Unrewarded time at the feed bunk (presence at the feed bunk when no feed was present) was also measured using 1-min scans. For each scan, unrewarded time at the feed bunk was defined when a heifer had her head completely past the feed rail and over an empty feed bunk. Total daily unrewarded time at the feed bunk was calculated for each day of the 7-d recording periods. Feeding competition, recorded as displacements from the feed bunk while feeding, was measured on $\mathrm{d} 16,18$, and 20 of each treatment period. A displacement was marked when a butt or a push from the actor (instigator) resulted in the complete withdrawal of the reactor's head from beneath the feed rail (DeVries et al., 2004). These observations 
were used to calculate the number of times each heifer was displaced from the feed bunk per day and per minute of feeding time. Further, these data were used to calculate an index of success in agonistic interactions for each individual heifer, according to DeVries et al. (2004), as follows: number of individuals subordinate to focal heifer/total number of individuals within a pen $x$ $100 \%$. Individuals were counted as subordinate to the focal animal when they were the reactor more often than the actor during interactions.

Lying behavior was recorded during the last $7 \mathrm{~d}$ of each treatment period. Daily lying times of individual heifers were collected using electronic data loggers (Hobo Pendant G Data Logger, Onset Computer Corp., Pocasset, MA), previously validated by Ledgerwood et al. (2010). These devices were placed on the hind leg of each heifer using veterinary bandaging (Vetrap Bandaging Tape, $3 \mathrm{M}$, St. Paul, MN) and measured the orientation of the leg at $1 \mathrm{~min}$ intervals. These data were summarized to calculate the average daily standing and lying time (min/d), as well as time spent standing without eating (i.e., daily standing time - feeding time).

Representative grab samples of the TMR were taken for DM and chemical analysis during the last $7 \mathrm{~d}$ (the recording weeks) of each treatment period. Samples of the dietary components were also taken for DM and chemical analysis once during each of the recording weeks. Duplicate samples of forage components were taken, once weekly during the recording weeks, for particle size separation. Grab samples of the TMR were also collected for particle size separation at the time of feed delivery twice weekly during the last $7 \mathrm{~d}$ of each treatment period. All samples were immediately frozen at $-20^{\circ} \mathrm{C}$ until they were analyzed. Samples for particle size separation were thawed at a later date and separated using a 3 -screen $(19,8,1.18 \mathrm{~mm})$ Penn State Particle Separator (PSPS; Kononoff et al., 2003). This separated the samples into 4 fractions: long $(>19$ $\mathrm{mm})$, medium $(<19,>8 \mathrm{~mm})$, short $(<8,>1.18 \mathrm{~mm})$ and fine $(<1.18 \mathrm{~mm})$ particles. After separation, DM of each separated fraction was determined by forcedair drying at $55^{\circ} \mathrm{C}$ for $48 \mathrm{~h}$. Samples taken for DM and chemical analysis were oven-dried at $55^{\circ} \mathrm{C}$ for $48 \mathrm{~h}$ and then ground to pass through a 1-mm screen (Wiley Mill, Arthur H. Thomas Co., Philadelphia, PA). These samples were then sent to Cumberland Valley Analytical Services Inc. (Maugansville, MD) for analysis of DM $\left(135^{\circ} \mathrm{C}\right.$; AOAC International, 2000 ; method 930.15), ADF (AOAC International, 2000; method 973.18), NDF with heat-stable $\alpha$-amylase and sodium sulfite (Van Soest et al., 1991), and CP $(\mathrm{N} \times 6.25$; AOAC International, 2000; method 990.03; Leco FP528 Nitrogen Analyzer, Leco, St. Joseph, MI).
Data for intakes, growth (ADG), feeding time, unrewarded time, lying and standing behavior, and competitive behavior were averaged for each pen by treatment period. Pen variance in ADG (ADGv) was determined by calculating the standard deviation of weekly heifer gain values within treatment periods. Feeding time variability was determined by calculating the standard deviation of daily values for individual heifers within a pen within treatment periods and then averaging by period. Data for feed bunk attendance (percentage of heifers at the feed bunk when feed was and was not present) was summarized by hour for each pen for each treatment period.

Preliminary screening of the data revealed that all dependent variables were distributed normally. To test for differences among treatments-DMI, ADG, ADGv, feeding and unrewarded time, feeding time variability, displacements, lying time, and time spent standing without eating - the MIXED procedure of SAS (SAS Institute, 2008) was used. The model included the fixed effects of period, feed delivery frequency, and bunk space, the random effect of pen, and the residual error; interactions of period and treatments were also tested in the model. To test the effect of treatment for diurnal feeding patterns, the data were analyzed using the MIXED procedure of SAS (SAS Institute, 2008), treating hour as a repeated measure. The model included the fixed effects of period, feed delivery frequency, bunk space, and hour, the random effect of pen, and the residual error. The covariance structure was autoregressive, according to the best-fit Schwarz's Bayesian information criterion.

Overall, treatment responses were tested using the pen as the experimental unit; however, we had a specific prediction that certain heifers would respond differently in behavior based on their index of success. Thus, the effect of treatment on ADG, ADGv, feeding time, feeding time variability, unrewarded time, and lying behavior was also evaluated using heifer as the observational unit and the heifers' index of success as a covariate. These data were analyzed using the MIXED procedure of SAS (SAS Institute, 2008); the model included the index of success as a covariate, the fixed effects of period, feed delivery frequency, and bunk space, the random effect of heifer within pen, and the residual error.

All values reported are least squares means. Significance was declared as $P \leq 0.05$ and trends were reported if $0.05<P \leq 0.10$.

There were no orts recorded throughout the study. As expected in a study with controlled feed amounts, DMI did not differ between treatments (Table 2). Although ADG was greater with increased feed bunk 
space, and tended to be greater when delivering feed $1 \times / d$, the variability of ADG within each pen did not differ (Table 2), indicating that treatment effects on growth were similar across animals within a pen. Heifers offered more feed bunk space may have been able to gain more than heifers with reduced bunk space because increased space allows all heifers to feed simultaneously, without interference from their neighbors, and provides sufficient space to avoid competition or more subtle social pressure (Albright, 1993; Collings et al., 2011). This increase in ADG might be due to a more stable rumen microbial population resulting from less overall fluctuation in rumen $\mathrm{pH}$ throughout the day, as observed by Greter et al. (unpublished data) through measurement of rumen temperature. Indeed, heifers provided with $0.40 \mathrm{~m}$ of bunk space were more feed efficient than heifers provided with $0.29 \mathrm{~m}$ (Table 2 ). Heifers fed $1 \times / d$ were not, however, more efficient than heifers fed $2 \times /$ d. Similarly, Greter et al. (unpublished data) found that heifers fed $1 \times / d$ were not more efficient than heifers fed $2 \times$ or $4 \times / d$. A tendency was noted for an interaction between feed bunk space and frequency of feed delivery on the feed efficiency of limit-fed dairy heifers, with heifers provided restricted bunk space being less efficient when fed $2 \times /$ d. Dayto-day variability in individual DMI within a pen and the restricted bunk space, in combination with smaller amounts of feed offered at each feed delivery, may have increased the jostling at the bunk or have affected individual feeding rates. As we were unable to measure individual DMI or feeding rate in this study, further work on this is encouraged.

It must be noted that, although all efforts were made to consistently deliver feed at $1200 \mathrm{~h}$, some day-to-day variability did occur; thereby affecting the diurnal feeding patterns (Figure 1). Analysis of the diurnal feed bunk attendance of heifers revealed no feed bunk space $\times$ hour interaction $(P=1.0)$, but did show a feed delivery frequency $\times$ hour interaction $(\mathrm{SE}=0.86$, $P<0.001$; Figure 1a) when feed was available. This indicated that feed bunk attendance differed as feed delivery frequency was altered, with more heifers at the feed bunk immediately following feed delivery when fed $1 \times / d$ but not when fed $2 \times / d$. This may have been because the length of time between feed deliveries affected the hunger status of the heifers. Overall, heifers fed $1 \times / \mathrm{d}$ spent more time feeding per day; this is consistent with previous research (Greter et al., unpublished data) wherein heifers fed $1 \times / d$ spent just over $1 \mathrm{~h}$ feeding, whereas heifers fed $2 \times / d$ or $4 \times / d$ spent $<1$ h feeding per day.

Heifers fed $1 \times / d$ were more competitive than heifers fed $2 \times /$ d (Table 2). Following acclimation to treatment, heifers may have recognized that a single feed delivery was all that was to be provided on a daily basis and, therefore, if they did not consume large amounts of feed upon delivery, they would not be able to consume enough to meet their requirements. As such, these heifers would compete more for feed than heifers fed $2 \times / d$ in an effort to ensure maximal feed intake. This finding is, however, contrary to previous research indicating that frequency of feed delivery does not affect displacements at the feed bunk in ad libitum-fed lactating dairy cows (Phillips and Rind, 2001; DeVries and von Keyserlingk, 2005) or limit-fed dairy heifers (Greter et al., unpublished data). Thus, further research on feeding management factors and the social behavior of animals fed under limit-feeding regimens is encouraged.

Restricted feed bunk space did not increase competition between heifers (Table 2). This is consistent with previous research in which providing limit-fed heifers with varied amounts of feed bunk space did not alter competitive interactions (Greter et al., 2011). However, the lesser amount of feed bunk space provided in that

Table 2. Intake and behavior measures from growing dairy heifers fed $1 \times$ or $2 \times$ daily (frequency) and provided with 0.40 or $0.29 \mathrm{~m}$ of bunk space

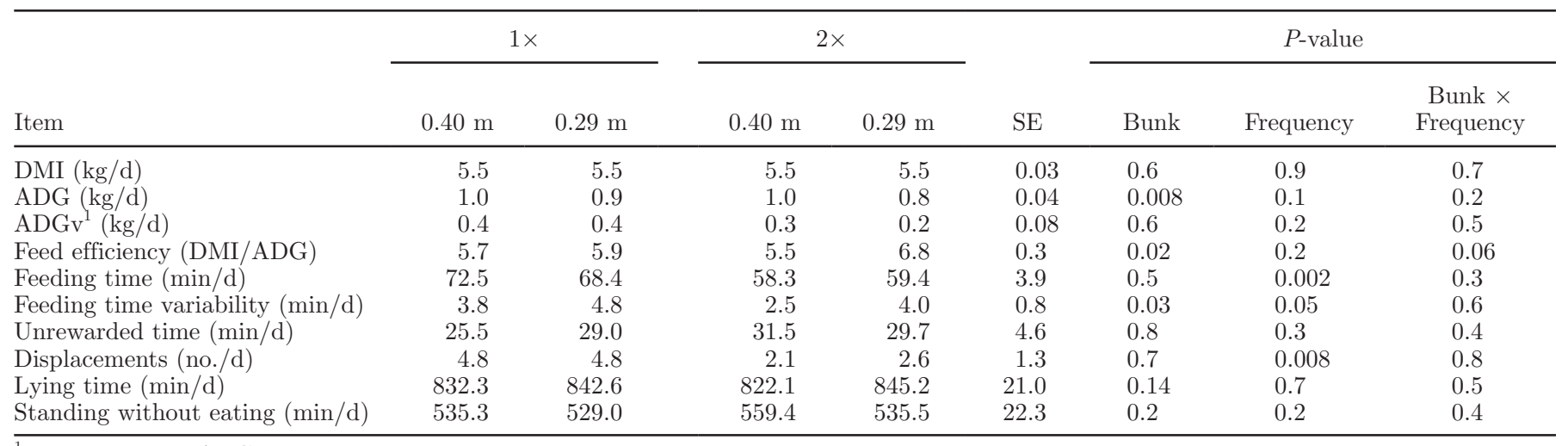

${ }^{1}$ Pen variance in ADG. 

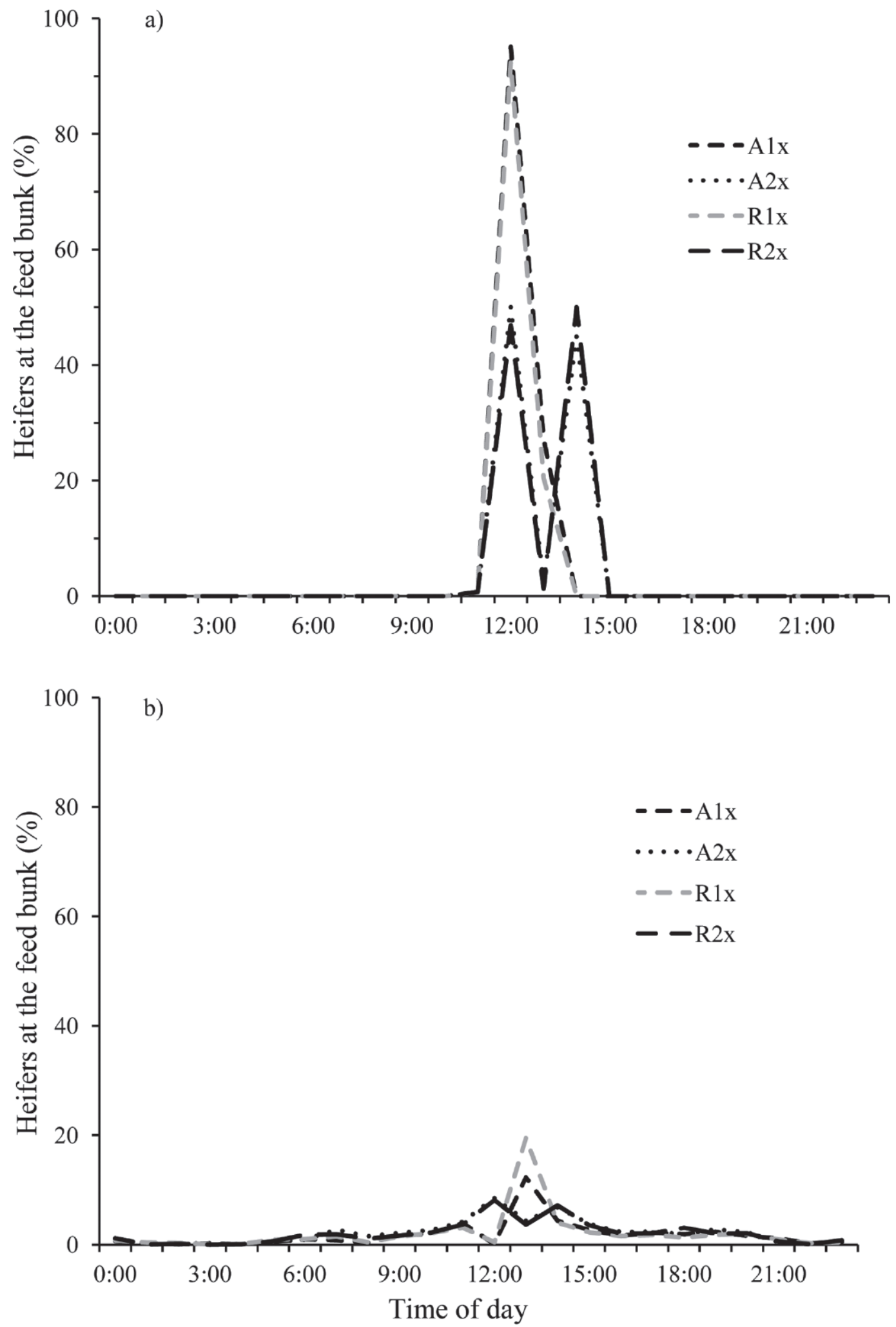

Figure 1. Percentage of heifers present at the feed bunk over a 24-h period (summarized by hour) for 4 treatments when (a) feed was available, and (b) no feed was available (unrewarded visits). Treatments were (1) adequate bunk space $(0.40 \mathrm{~m} / \mathrm{heifer})$ fed $1 \times(1200 \mathrm{~h})$ each day (A1x), (2) adequate bunk space $(0.40 \mathrm{~m} /$ heifer $)$ fed $2 \times(1200$ and $1400 \mathrm{~h})$ each day $(\mathrm{A} 2 \mathrm{x}),(3)$ restricted bunk space $(0.29 \mathrm{~m} / \mathrm{heifer})$ fed $1 \times$ each day $(\mathrm{R} 1 \mathrm{x})$, and $(4)$ restricted bunk space $(0.29 \mathrm{~m} /$ heifer $)$ fed $2 \times$ each day $(\mathrm{R} 2 \mathrm{x})$. Data were averaged across $7 \mathrm{~d}$ for 4 pens $(4$ heifers/pen) on each treatment. 
study allowed for $0.34 \mathrm{~m} /$ heifer, which was sufficient to allow all animals to feed simultaneously. In the current study, although bunk space was restricted to $0.29 \mathrm{~m} /$ heifer, all heifers were still able to feed simultaneously, although with difficulty and in tight arrangement. It seems, therefore, that limit-fed heifers are so motivated to feed that they will forego competitive interactions in an effort to obtain as much feed as possible (Kitts et al., 2011). Longenbach et al. (1999) found that restricting feed bunk space (to as little as $0.15 \mathrm{~m} /$ heifer) for limit-fed heifers increased competition at the feed bunk and that this competition decreased as feed bunk length increased. Longenbach et al. (1999) restricted feed bunk space much more severely than was done in the present study. As such, competition would likely become more severe with increasingly restricted space allowance. In the current study, index of success did not affect an individual's response to treatment and, therefore, will not be discussed further. Despite the lack of difference in displacements between treatments, decreased feed bunk space and delivering feed $1 \times / \mathrm{d}$ did result in greater within-day variability in feeding time between heifers within a pen than increased feed bunk space and delivering feed $2 \times / \mathrm{d}$ (Table 2 ). It is likely that feeding time is related to social factors existing at the feed bunk. Cattle have established hierarchies in which subordinates do not feed near dominant animals (Manson and Appleby, 1990). When feed bunk space is restricted and feed is provided in a limited amount, it is likely that subordinate animals must alter their behavioral time budget in an effort to obtain sufficient feed for their metabolic requirements and growth. Aggression may increase in all heifers managed under conditions of restricted bunk space, resulting in increased jostling for position and pressure from conspecifics at the bunk (Rutter et al., 1987; Longenbach et al., 1999). The increased motivation of limit-fed animals may be such that complete displacements from the feed bunk (as defined by DeVries et al., 2004) do not occur as a result of feeding disruptions at the bunk (i.e., nudges or other actions unable to be recognized through video analysis). Rather, this competitive activity may result in increased variability in feeding times between individuals within a pen. As we were unable to measure individual intakes, it is unclear whether heifers spending more time feeding also consumed more feed; thus we encourage further work in this area.

The amount of unrewarded time at the feed bunk (present at the bunk with no feed available) did not differ between treatments. This may have been an artifact of the experimental design, with different treatments assigned to adjacent pens. As cattle are known to synchronize their behavior (Rook and Huckle, 1995), it appears that one heifer visiting the empty bunk would prompt other heifers to do the same. The majority of unrewarded visits surround feeding time (Figure 1a and b), and it seems that heifers fed $1 \times / d$ are still present at the empty bunk when heifers fed $2 \times / \mathrm{d}$ are being fed the second time. Heifers fed $2 \times / d$ spread their unrewarded visits more evenly across the feeding period, possibly reflecting dissatisfaction associated with lack of foraging or continuation of hunger (lack of satiety from smaller meals).

Heifers spent a similar daily amount of time lying down and standing without eating across all treatments (Table 2). This is in agreement with a previous study examining the effects of feed delivery frequency on the behavior of limit-fed heifers (Greter et al., unpublished data) and has also been demonstrated in studies with adult cattle (DeVries and von Keyserlingk, 2005; Robles et al., 2007). The effect of feed bunk space on lying behavior has not been examined in previous work with limit-fed dairy heifers. Although this is the first study identifying no effect of feed bunk space on time spent standing without eating in limit-fed heifers, previous research examining frequency of feed delivery has shown that heifers fed more frequently $(2 \times$ or $4 \times / d)$ spent more time standing without eating than heifers fed $1 \times / d$ (Greter et al., unpublished data). Heifers in the current study were more variable in their lying time than heifers in the study conducted by Greter et al. (unpublished data), which translated into greater variability in time spent standing without eating. As such, despite a difference in feeding time, no overall effect of frequency of feed delivery on time spent standing without eating was noted.

Overall, we observed no interactions between feed bunk space and feed delivery frequency on the feeding behavior of limit-fed dairy heifers. However, providing $0.40 \mathrm{~m}$ versus $0.29 \mathrm{~m}$ of feed bunk space per heifer increased ADG and minimized the variability in feeding time between individuals within a pen. Delivering feed $1 \times / d$ also contributed to a tendency for greater ADG and increased daily time spent feeding. However, delivering feed $1 \times / d$ also resulted in more variability in feeding time between heifers within a pen and an increase in competitive interactions at the feed bunk. From these results, we recommend providing adequate feed bunk space to allow limit-fed heifers to comfortably feed simultaneously (i.e., not restricted or forced to feed close to dominant heifers). Furthermore, delivering a limit-fed ration $1 \times / d$ will enable the heifers to gain adequate weight and spend more time feeding per day, but may also result in increased competition for feed.

\section{ACKNOWLEDGMENTS}

We thank the staff and students at the University of Guelph, Kemptville Campus, Dairy Education and 
Research Centre, particularly Megan Bruce, Bianca Kitts, Alexa Main, and Nancy Stonos for their technical help and support. Angela Greter was supported by a Natural Sciences and Engineering Research Council of Canada (NSERC, Ottawa, Ontario, Canada) Alexander Graham Bell Canadian Graduate Scholarship. This project was funded through an Ontario Ministry of Agriculture, Food and Rural Affairs (OMAFRA, Guelph, Ontario, Canada)/University of Guelph Production Systems research grant. This project was also supported through contributions from the Canadian Foundation for Innovation (CFI, Ottawa, Ontario, Canada) and the Ontario Research Fund (Ministry of Research and Innovation, Toronto, Ontario, Canada).

\section{REFERENCES}

Albright, J. L. 1993. Feeding behavior of dairy cattle. J. Dairy Sci. $76: 485-498$.

AOAC International. 2000. Official Methods of Analysis. Vol. I. 17th ed. AOAC International, Arlington, VA.

Beauchemin, K. A., L. Eriksen, P. Nørgaard, and L. M. Rode. 2008. Salivary secretion during meals in lactating dairy cattle. J. Dairy Sci. 91:2077-2081.

Canadian Council on Animal Care. 2009. Guidelines On: The care and use of farm animals in research, teaching and testing. Canadian Council on Animal Care, Ottawa, ON, Canada.

Collings, L. K., D. M. Weary, N. Chapinal, and M. A. G. von Keyserlingk. 2011. Temporal feed restriction and overstocking increase competition for feed by dairy cattle. J. Dairy Sci. 94:5480-5486.

DeVries, T. J., and M. A. G. von Keyserlingk. 2005. Time of feed delivery affects the feeding and lying patterns of dairy cows. J. Dairy Sci. 88:625-631.

DeVries, T. J., M. A. G. von Keyserlingk, and D. M. Weary. 2004 Effect of feeding space on the inter-cow distance, aggression, and feeding behavior of free-stall housed lactating dairy cows. J. Dairy Sci. 87:1432-1438

Greter, A. M., B. L. Kitts, and T. J. DeVries. 2011. Limit feeding dairy heifers: Effect of feed bunk space and provision of a low-nutritive feedstuff. J. Dairy Sci. 94:3124-3129.

Hoffman, P. C., C. R. Simson, and M. Wattiaux. 2007. Limit feeding of gravid Holstein heifers: Effect on growth, manure nutrient excretion, and subsequent early lactation performance. J. Dairy Sci. 90:946-954.

Keys, J. E., R. E. Pearson, and P. D. Thompson. 1978. Effect of feedbunk stocking density on weight gains and feeding behavior of yearling Holstein heifers. J. Dairy Sci. 61:448-454.

Kitts, B. L., I. J. H. Duncan, B. W. McBride, and T. J. DeVries. 2011. Effect of the provision of a low-nutritive feedstuff on the behavior of dairy heifers fed a high-concentrate ration in a limited amount. J. Dairy Sci. 94:940-950.

Kononoff, P. J., A. J. Heinrichs, and D. R. Buckmaster. 2003. Modification of Penn State forage and total mixed ration particle separator and the effects of moisture content on its measurements. J. Dairy Sci. 86:1858-1863.

Lascano, G. J., G. I. Zanton, F. X. Suarez-Mena, and A. J. Heinrichs. 2009. Effect of limit feeding high- and low-concentrate diets with Saccharomyces cerevisiae on digestibility and on dairy heifer growth and first-lactation performance. J. Dairy Sci. 92:51005110.

Ledgerwood, D. N., C. Winckler, and C. B. Tucker. 2010. Evaluation of data loggers, sampling intervals, and editing techniques for measuring the lying behavior of dairy cattle. J. Dairy Sci. 93:5129-5139.

Longenbach, J. I., A. J. Heinrichs, and R. E. Graves. 1999. Feed bunk length requirements for Holstein dairy heifers. J. Dairy Sci. 82:99-109.

Manson, F. J., and M. C. Appleby. 1990. Spacing of dairy cows at a food trough. Appl. Anim. Behav. Sci. 26:69-81.

Moody, M. L., G. I. Zanton, J. M. Daubert, and A. J. Heinrichs. 2007. Nutrient utilization of differing forage-to-concentrate ratios by growing Holstein heifers. J. Dairy Sci. 90:5580-5586.

NRC. 2001. Nutrient Requirements for Dairy Cattle. Natl. Acad. Sci Washington, DC.

Phillips, C. J. C., and M. I. Rind. 2001. The effects of frequency of feeding a total mixed ration on the production and behavior of dairy cows. J. Dairy Sci. 84:1979-1987.

Quigley, J. D., T. M. Steen, and S. I. Boehms. 1992. Postprandial changes of selected blood and ruminal metabolites in ruminating calves fed diets with or without hay. J. Dairy Sci. 75:228-235.

Robles, V., L. A. Gonzalez, A. Ferret, X. Manteca, and S. Calsamiglia. 2007. Effects of feeding frequency on intake, ruminal fermentation, and feeding behavior in heifers fed high-concentrate diets. J. Anim. Sci. 85:2538-2547.

Rook, A. J., and C. A. Huckle. 1995. Synchronization of ingestive behavior by grazing dairy cows. Anim. Sci. 60:25-30.

Rutter, S. M., D. A. Jackson, C. L. Johnson, and J. M. Forbes. 1987. Automatically recorded competitive feeding behavior as a measure of social dominance in dairy cows. Appl. Anim. Behav. Sci. $17: 41-50$.

SAS Institute. 2008. User's Guide: Statistics. Version 9.1.3 ed. SAS Institute Inc., Cary, NC

Stanton, A. L., D. F. Kelton, S. J. LeBlanc, S. T. Millman, J. Wormuth, R. T. Dingwell, and K. E. Leslie. 2010. The effect of treatment with long-acting antibiotic at postweaning movement on respiratory disease and on growth in commercial dairy calves. J. Dairy Sci. 93:574-581.

Van Soest, P. J., J. B. Robertson, and B. A. Lewis. 1991. Methods for dietary fiber, neutral detergent fiber and nonstarch polysaccharide in relation to animal nutrition. J. Dairy Sci. 74:3583-3597.

Zanton, G., and J. Heinrichs. 2008. Precision feeding dairy heifers: Strategies and recommendations. Pennsylvania State Univ. DAS08-130. Pennsylvania State Univ., University Park. 